\title{
Prediction of Extent of Corrosion using Electrical Resistivity
}

\section{Sajna K R}

Post Graduate student, Department of Civil Engineering Sree Narayana Gurukulam College of Engineering Ernakulam, Kerala, India

\author{
Jeena Mathew \\ Department of Civil Engineering \\ Sree Narayana Gurukulam College of Engineering \\ Ernakulam, Kerala, India
}

\begin{abstract}
Corrosion of concrete structures has been one of the major causes of structural failure. The progress of corrosion cannot be visually assessed until a crack or a delamination appears. Early detection of the corrosion could help limit the location and the extent of necessary repairs or replacement, as well as reduce the cost associated with rehabilitation work. The corrosion process can be tracked using several electrochemical techniques. Most commonly the half-cell potential measurement technique is used for this purpose. Through this paper, an extensive literature review is made in relationship between electrical resistivity and rate of corrosion. This paper also reviews and assesses research concerning the influential parameters such as method of measuring rate of corrosion, effect of curing condition, diameter of rebar and cover on measuring electrical resistivity of concrete. Moreover, concrete resistivity concept, application, and combined use of the four point Wenner concrete resistivity method and the half-cell potential method are introduced.
\end{abstract}

\section{Keywords - Electrical resistivity, Rate of corrosion}

\section{INTRODUCTION}

Corrosion of the steel reinforcement in concrete is a crucial problem for the construction industry since it poses the most serious risk to the structural integrity of reinforced concrete structures. Inspection and monitoring techniques are needed to assess the corrosion of the reinforcement in order to maintain, protect, and repair buildings. In the last few years much attention has been given to developing techniques for predicting the remaining service life of concrete structures .Most of the reported research in this area focuses on the corrosion of concrete reinforcement. Several electrochemical techniques for monitoring and assessing the corrosion of steel in concrete structures.

Linear polarization resistance (LPR) method commonly used for measuring rate of corrosion. The Linear Polarization Resistance (LPR) does make a direct assessment of the rate of corrosion, but it requires a direct electrical connection to the steel reinforcement. In addition LPR requires knowledge or an assumption of the area of steel reinforcing bar being perturbed. There for we want to research on this topic. The four-point resistivity method enables one to determine the severity of corrosion in a quick and non-destructive manner. The rebar undergo active corrosion when concrete resistivity $\rho$ is below $10 \mathrm{k} \Omega \mathrm{cm}$, whereas at concrete resistivity $\rho$ above $30 \mathrm{k} \Omega \mathrm{cm}$ the probability of their corrosion is low.

It is well known that the probability of corrosion in concrete structures depends on the ionic conductivity of the concrete electrolyte, the humidity, the temperature, and the quality of the concrete cover. The ionic conductivity is measured quantitatively as the resistivity of the concrete. Concrete resistivity $\rho$ ranges widely from 101 to $106 \Omega \mathrm{m}$, depending on mainly the moisture content and the material of the concrete. One of the promising techniques of measuring concrete resistivity is shown in Figure1, concrete resistivity $\rho$ is inversely proportional to the corrosion rate. The effect of mortar resistivity is strongly dependent on the relative humidity of the environment. The amount of pores in concrete determines its resistivity $\rho$ and corrosion rate.

In this paper, the correlation between electrical resistivity and corrosion of concrete is discussed. This paper reviews the effect of several influencing parameters such as external environment and concrete mixture, effect of curing condition, diameter of rebar, cover of concrete on the electrical resistivity.

\section{CORRELATION BETWEEN ELECTRICAL RESISTIVITY AND RATE OF CORROSION}

Lukasz Sadowski [1], state that systematic methodology for assessing the probability of corrosion in concrete slabs through combined half-cell potential and concrete resistivity measurements, this paper proposes such a methodology based on the combined use of the four point Wenner concrete resistivity method and the half-cell potential method.

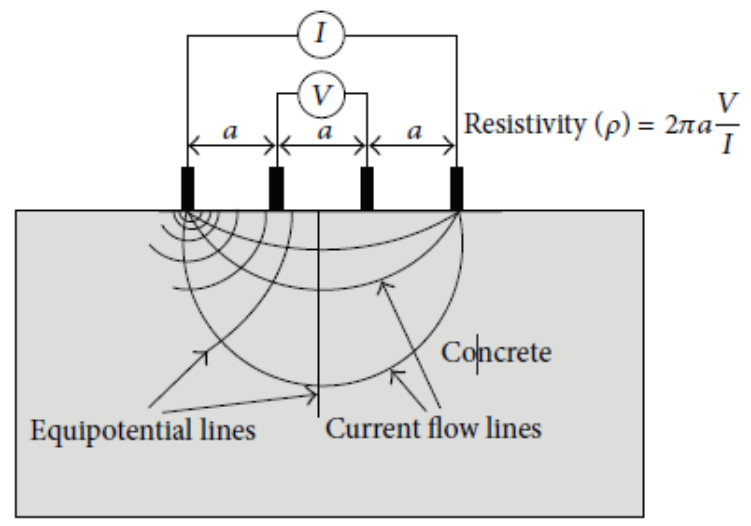

Fig.1.Concrete resistivity measurement 


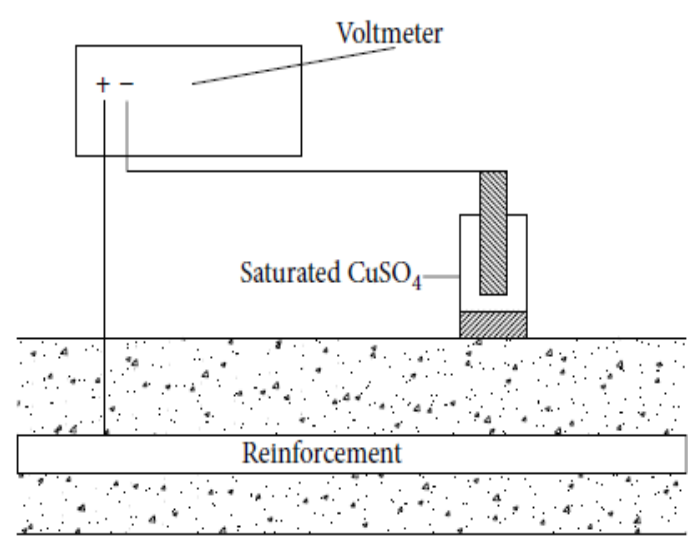

Fig.2.Half-cell potential measurements

Comparative tests were carried out using the two methods to determine the probability of corrosion in model test concrete slab specimens. The experimental results showed that the two non-destructive techniques can be used together in order to obtain maximum information about the probability of corrosion in a tested structure. This study was motivated by the engineer's need for a combination of the half-cell potential mapping technique and concrete resistivity measurements to more accurately assess the probability of corrosion. The combined techniques can be used in both the field and the laboratory environment. Moreover, they can be automated and integrated into monitoring systems for new or existing reinforced concrete structures. However, it is still recommended to perform additional tests for other rebar diameters, different aggregate grading, and a wider range of covers.

C. Andrade et.al [2], stated that Corrosion of steel reinforcement can propagate unseen until expansive corrosion products cause cracking or spalling of the concrete cover. The traditional assessment methods are the half-cell potential mapping technique and the concrete resistivity method but they do not give a direct measurement of the ongoing rate of corrosion. The Linear Polarisation Resistance (LPR) does make a direct assessment of the rate of corrosion, but it requires a direct electrical connection to the steel reinforcement. In addition LPR requires knowledge or an assumption of the area of steel reinforcing bar being perturbed. This paper reports on a novel adaptation of the resistivity and LPR methods to provide an evaluation of the ongoing rate of corrosion without the need to breakout the concrete cover and expose steel reinforcement and without the need to evaluate the area of perturbation.

This study has shown that the short-circuit influence of an embedded steel bar in the vicinity of a concrete resistivity measurement can be used to evaluate the rate of ongoing corrosion on the surface of the bar. From a pilot study of just three specimens a good correlation has been found with conventional LPR measurements. Further study is required to validate this method over a wider range of conditions and configurations.

C. Alonso et.al [3], stated that corrosion rate and simultaneous electrical resistance values of rebars in mortar fabricated with six different types of cements are given and the relation between those values is presented. The specimens were carbonated in order to promote active corrosion of the rebars. They were held in chambers with different relative humidities.

The results of this study indicate a strong relationship between the corrosion rate measured on the rebars (by means of Polarization Resistance method) and the electrical resistance of the concrete, which suggests a method of estimating the rebar corrosion rate from the simple measurement of the electrical resistance when rebars are depassivated. The relation between i $\mathrm{r}$ and $\mathrm{R}$ obtained is quite similar in all the cases and suggests concrete electrical resistivity may act as a "controlling" factor of the corrosion rate.

Karla Hornbostel [4], addressed the relationship between corrosion rate and concrete resistivity. It is widely accepted that concrete resistivity can easily be measured, especially in the field, compared to other parameters in corrosion science such as the corrosion rate. A relationship between concrete resistivity and corrosion rate would consequently allow the assessment of the corrosion stage in an efficient and reasonably priced way. This can be seen as the main reason for the intensive research over the last decades on the $\mathrm{C}-\mathrm{R}$ relationship. This report reviews and evaluates literature on experimental investigations, compares their results, and identifies differences between them.

A clear tendency can be found that with increasing concrete resistivity, the corrosion rate decreases. The relationship can be observed once corrosion has started (active conditions). It will not be valid in the case of saturated concrete, where although the resistivity is low, the corrosion rate will still be small due to a lack of oxygen. Different parameters were identified which might have an influence on the $\mathrm{C}-\mathrm{R}$ relationship. However, there are still several factors which need intense discussion and investigation. It can be concluded that although the concrete resistivity seems promising for the assessment of Service Life of reinforced concrete structures, it is necessary to investigate its relationship to the corrosion rate further.

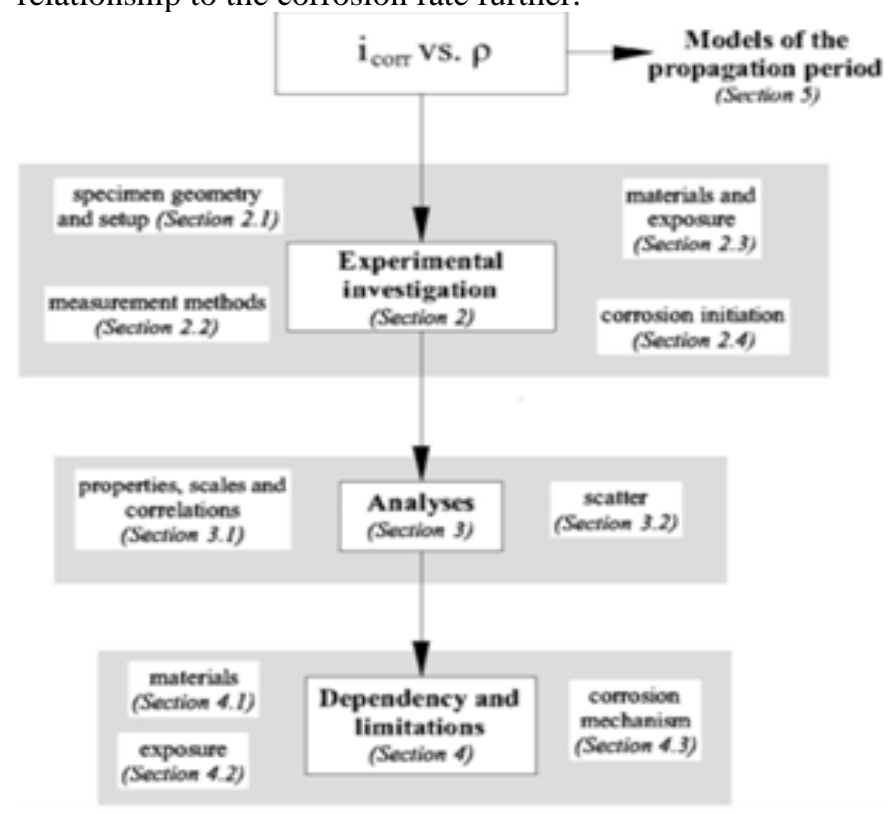

Fig.2.Outline of the literature review 
W. Morris [5], stated that in order to determine the existence of such correlation, certain electrochemical parameters as the corrosion potential (Ecorr) and current density (icorr) are investigated together with concrete resistivity and chloride concentration data.t. A relationship between chloride threshold values for rebar corrosion initiation and resistivity values (indicative of concrete quality) is proposed. The results also showed that the risk for chloride-induced corrosion and the chloride threshold value that will initiate the corrosion process can be estimated via a straight forward and non-destructive technique like concrete resistivity. Further investigations are currently undertaken so as to take into account the effect of mortars and concretes of varying compositions.

G. K. Glass [6], established a model, termed anodic resistance control, resistivity is viewed as a factor which may limit a half reaction rate in a similar way to diffusion and activation polarization. It is also shown that, when such a model is operating, the use of polarization resistance to monitor corrosion rate changes may still be justified provided the cathodic reaction rate is an exponential function of potential. The corrosion rate of steel in carbonated mortars is under anodic control with the anodic reaction rate being limited by the mortar resistivity. Thus resistivity controls a half reaction rate in a similar way to diffusion and activation polarization in other conditions. This may be termed anodic resistance control.

It is widely accepted that concrete resistivity can easily be measured, especially in the field, compared to other parameters in corrosion science such as the corrosion rate [7]. A relationship between concrete resistivity and corrosion rate would consequently allow the assessment of the corrosion stage in an efficient and reasonably priced way. This can be seen as the main reason for the intensive research over the last decades on the $\mathrm{C}-\mathrm{R}$ relationship. Assessment criteria to quantify corrosion activity by concrete resistivity measurements can be found in the literature. However, a high variation between the threshold values is observed.

An upper limit of 1000-2000 X m can be identified from the comparison over which the corrosion rate will be low. As a lower limit, concrete with a resistivity under $50 \mathrm{X}$ $\mathrm{m}$ is likely to allow heavy corrosion.

Among all the studies conducted so far, there is an agreement that corrosive environment in reinforced concrete and electrical resistivity of concrete have an inverse relationship. As the electrical resistivity of concrete decreases, the rate of steel reinforcement corrosion increases. A theory by Glasset al. [6], stated that the corrosion rate of reinforced concrete is under anodic control with the anodic reaction being limited by the mortar resistivity. Glass's anodic resistance theory is also supported by studies conducted by Morris et al. [5], and Bertolini and Polder [11]. In their investigations, it has been found that concrete resistivity affected not only corrosion rate, but also the corrosion potential $[5,11]$.

\section{PARAMETERS INFLUENCING ON ELECTRICAL RESISTIVITY}

\section{A. W/C Ratio of concrete}

Generally, water to cement (w/c) ratio is one of the main factors contributing in permeability of concrete and its properties.

T. Rupnow et.al [7], stated that that higher w/c ratio results in a high percentage of porosity (more voids) and leads to a lower electrical resistivity value indicating a more permeable concrete[31].However, concrete containing supplementary cementitious materials such as slag showed an irregular behavior for various w/c ratios. For instance, an increase in w/c ratio from 0.35 to 0.65 caused an increase in electrical resistivity values, which means a less permeable concrete. Additionally the electrical resistivity measurements are affected by the degree of hydration as further hydration typically reduces the concrete porosity and how these pores are interconnected.

Van Noort et al [8], state that different concrete compositions with various $\mathrm{w} / \mathrm{c}$ ratio ranges also indicated that concrete's electrical conductivity increased as w/c ratio increased. Within a hardened concrete matrix, electrical conduction flows through the fluid contained in the pores; therefore the relative volume of interconnected pores controls the concrete's electrical resistivity. Increasing the w/c ratio (at fixed cement content) leads to a higher volume fraction of hydrated cement paste in the concrete mix and results in higher concrete electrical conductivity.

\section{B. Effect of curing condition}

Weiss et al [9], performed numerical study attempted to simulate a mortar with a water to cement ratio of 0.42 with three curing conditions: (a) sealed during curing and testing, (b) sealed during curing and saturated during testing, and (c) saturated during curing and testing. It was concluded that the specimen that was sealed during both curing and testing had the highest resistivity whereas the sample that was sealed during curing and saturated at the time of testing had the lower most resistivity. This difference can be explained by the saturation degree of the sample. The results recommend that storing a sample underwater in the lab may cause a remarkably different degree of hydration than what may occur in a field structure. The sample that was continually saturated and the sample that was sealed and saturated at the time of testing had a similar resistivity for the same degree of hydration; however, the continually saturated sample had a higher degree of hydration at the same age.

\section{Presence of rebar}

S. G. Millard and K. R. Gowers [10], utilized an experimental setup with steel rebar in the tanks filled with conductive medium solution and its finite element modelling in order to study the effects of concrete cover thickness as well as rebar diameter and spacing on concrete resistivity using four-point Wenner probe. According to this study, distance between the probe and embedded rebar was found to be the main influential parameter when measurements were taken on top of the bar. It was also reported that rebar diameter is not impactful in its disturbance. Moreover, it was 
found that measurement errors were increased by reducing rebar spacing while measurements are taken between two parallel rebars. However, it should be noted that results were obtained from measurements on the conductive solution tank and not from real concrete block. Similar study of resistivity measurements utilizing Wenner probe on concrete block with embedded steel reinforcements showed that orienting the probe perpendicular to reinforcements significantly reduced their influence on resistivity measurements.

\section{CONCLUSION}

Through an extensive literature review, this paper identifies several factors which might have potential influence on the electrical resistivity of concrete. Strong correlation can be found between increasing electrical resistivity of concrete and the corrosion rate. Concrete electrical resistivity may act as a "controlling" factor of the corrosion rate. The relationship can be seen when corrosion has initiated (active conditions). It will not be valid in the case of saturated concrete, where although the resistivity is low, the corrosion rate will be small because of lack of oxygen. Just a few studies could be found to identify the relationship between resistivity and rate of corrosion there for more investigations are still needed.

It can be concluded that still large range and scatter exist for correlation between corrosion rate and concrete resistivity. Also, effect of moisture state and temperature as well as corrections to corrosion rate measurements should be considered during an investigation on finding correlation between resistivity and corrosion rate. Knowledge is still lacking in the literature to understand which mechanism dominates the corrosion process and how resistivity measurements are impacted. To practically determine the corrosion and resistivity relationship, more field data should be collected and analyzed.

\section{FURTHER SCOPE}

In this study, influence of various parameters on resistivity is being studied (parameters: cover thickness, crystalline water-proofing admixtures effect, and cement type). Grade of concrete, curing medium and rebar presents influences electrical resistivity. However, it is still recommended to perform additional tests for determine effect of different rebar diameters, different grade of concrete, and a wider range of covers during corrosion. Also want to find the relationship between resistivity and rate of corrosion of concrete members which is submerged in sea.

\section{REFERENCES}

[1] Lukasz Sadowski (2013) "Methodology for Assessing the Probability of Corrosion in Concrete Structures on the Basis of Half-Cell Potential and Concrete Resistivity Measurements", The Scientific World Journal Volume 2013, Article ID 71450.

[2] C. Andrade et.al (2004). "Test methods for on-site corrosion rate measurement of steel reinforcement in concrete by means of the polarization resistance method" Materials and Structures' / Mat6riaux ET Constructions, Vol. 37.

[3] C. Alonso et al. (1988). "Relation Between Resistivity And Corrosion Rate Of Reinforcements In Carbonated Mortar Made With Several Cement Types", Cement And Concrete Research. Vol. 8.

[4] Karla Hornbost et.al (2013)" Relationship between concrete resistivity and corrosion rate - A literature review" @2013 Elsevier Ltd. All rights reserved.

[5] W. Morris, A. Vico, M. Vazquez, and S. R. de Sanchez, "Corrosion of reinforcing steel evaluated by means of concrete resistivity measurements," Corrosion Science, vol. 44, no. 1, pp. 81-99,2002.

[6] G. K. GLASS (1991)" Factors Affecting The Corrosion Rate Of Steel In Carbonated Mortars "Corrosion Science, Vol. 32, No. 12, pp. 1283 1294, 1991

[7] T. Rupnow and P. Icenogle, "Evaluation of surface resistivity measurements as an alternative to the rapid chloride permeability test for quality assurance and acceptance," Tech. Rep. 2290, Performing Organization Name and Address Louisiana Transportation Research Centre, Baton Rouge, La, USA, 2012.

[8] R. Van Noort, M. Hunger, and P. Spiesz, "Long-term chloride migration coefficient in slag cement-based concrete and resistivity as an alternative test method," Construction and Building Materials, vol.115, pp.746-759, 2016.

[9] J.Weiss,et.al (2013)"Using a saturation function to interpret the electrical properties of partially saturated concrete, "Journal of Materials in Civil lEngineering,vol.25, no.8,pp.1097-1106,2013.

[10] K. R. Gowers and S. G. Millard(1999), "Measurement of concrete resistivity for assessment of corrosion severity of steel using wenner technique,"ACI Materials Journal,vol.96,no.5,1999

[11] L. Bertolini and R. Polder, Concrete resistivity and reinforcement corrosion rate as a function of temperature and humidity of the environment TNO97-NaN-R0574,NetherlandsOrganisation for Applied Scientific Research, Delft, The Netherlands, 1997. 